\title{
Los usuarios, los contenidos y la inversión, elementos claves en la reformulación de la comunicación digital de las instituciones culturales
}

\author{
Laia Chic Pujol | historiadora del arte \\ URL de la contribución <www.iaph.es/revistaph/index.php/revistaph/article/view/4793>
}

Las nuevas tecnologías se han convertido en un elemento esencial en la vida de la sociedad actual; gracias a ellas, las personas están más conectadas e informadas que nunca. Es indudable el éxito e importancia que estas han adquirido, convirtiéndose en plataformas claves para cualquier empresa, incluido las instituciones culturales.

A pesar de las reticencias iniciales, las organizaciones ya han visto el potencial y los beneficios de las nuevas tecnologías en el campo de la cultura y de las artes. La realidad aumentada y la realitad virtual que permiten las visitas inmersivas y ofrecer más información a los usuarios potenciando de este modo los discursos y contenidos se han acabado convirtiendo en herramientas tecnológicas usuales en muchas corporaciones. Un ejemplo del uso de las tecnologías digitales en discursos culturales es el Mori Building Digital Museum de Tokyo, donde se brinda a los visitantes exposiciones inmersivas utilizando todas las tecnologías digitales que tienen a su alcance. Como puntualiza Albert Sierra, responsable de nuevas tecnologías de la Agencia Catalana de Patrimoni Cultural, el nuevo visitante no se conforma únicamente con "mirar" sino que busca tener "experiencias". A pesar de esta apertura tecnológica, las instituciones aún se muestran reacias en el uso de la comunicación digital $\mathrm{y}$, en especial, las redes sociales (RRSS) como mecanismo para comunicarse con su público. Es en este punto, el potencial y los errores que la comunicación digital y las RRSS tienen en las instituciones culturales, donde se centra el presente texto crítico.

Durante los meses de cuarentena causada por el COVID-19, las instituciones culturales se han visto forzadas a cambiar su estrategia de comunicación digi- tal por un modelo basado en nuevas plataformas para atraer y mantener a nuevos usuarios. Un punto que las entidades deben consolidar como base es que, en la actualidad, han de esforzarse más que nunca para ser relevantes para su comunidad. El éxito ya no se mide en el número de interacciones (los likes, los corazones, los retweets) sino en la calidad de la comunicación que se va a difundir. Es en esta materia donde las instituciones culturales juegan con ventaja; la cantidad y cualidad de contenidos que poseen de partida. Tratar estos de forma correcta, adaptarlos a cada red social en la que se tenga presencia y conocer e involucrar a los usuarios serán los elementos claves para poder conseguir una buena comunicación digital.

A nivel español se pueden ver dos tipos de comunicación digital: una más tradicional, basada en la publicación en la web de archivos y contenidos que pueden ser consultados libremente por los usuarios; y una comunicación más centrada en RRSS que busca la interacción con los usuarios. En esta primera línea, es donde se sitúa gran parte de las webs corporativas de las institu-

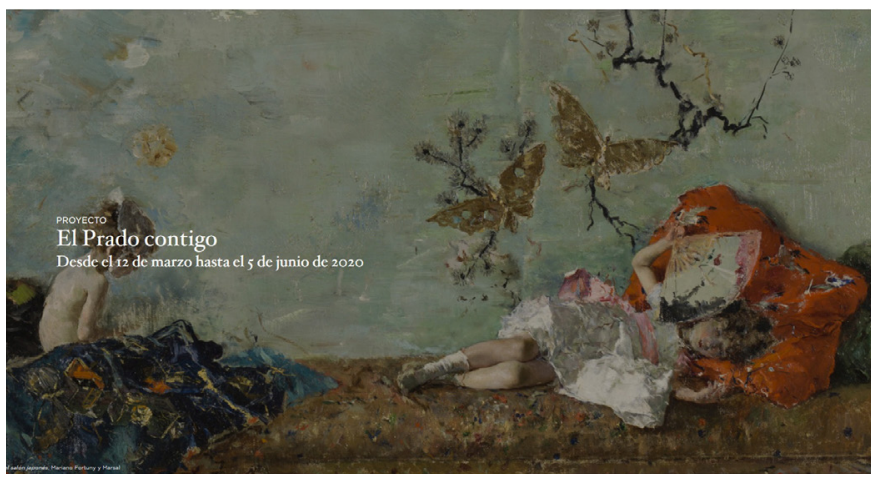

El éxito de \#PradoContigo conllevó la inversión tecnológica del museo 
a debate Comunicación y redes sociales en instituciones culturales

| coordina Candela González Sánchez

ciones; en ellas se pueden consultar el catálogo, textos reflexivos sobre exposiciones generados desde la propia organización, recursos audiovisuales, información práctica, etc. Aquí se incluirían muchas de las actividades que se han realizado, como la iniciativa \#PradoContigo en la que especialistas del museo comentaban las obras y las salas ${ }^{1}$. En esta se puede observar uno de los principales problemas que tienen las organizaciones culturales respecto a la comunicación online: la falta de madurez de los contenidos y la incapacidad de interacción con los usuarios. Es en este punto donde deben cambiar las cosas. Como apunta Ainhoa Simón Diez, se han de buscar nuevos códigos para reformular la comunicación digital y la presencia en las redes, teniendo al usuario como elemento central.

En los últimos años ha aparecido un gran número de aplicaciones en las que el rol del usuario ha sufrido un importante variación; son consumidores de contenido pero también son creadores de este. Esto es un elemento que las instituciones deben de tener muy en cuenta si pretenden adquirir nuevos usuarios y crear un mayor engagement en sus redes. Por tanto, como puntualiza Simón Diez (2020) "museums must become centres of inspiration that encourage the creative process"; es decir, no deben de abandonar esta línea más académica de educar al usuario, pero este se debe ver como un ente que puede crear contenido y con el que se debe establecer una relación. Un ejemplo de ello es la iniciativa que se desarrolló desde el Museo Nacional d'Art de Catalunya. A través del hashtag \#RepteArtACasa, se pedía a los usuarios recrear obras de su fondo artístico². Aquí se puede observar cómo se han llevado a cabo dos estrategias de comunicación diferentes: que los usuarios consulten el fondo online del museo y que estos creen un nuevo contenido que pudiese interesar a otros usuarios fuera de la comunidad digital del MNAC. Es en esta estrategia donde se debe dirigir la comunicación digital de las instituciones culturales.

A pesar de este nuevo interés por la actividad digital, también se han podido vislumbrar otros problemas más relacionados con departamentos técnicos y humanos.

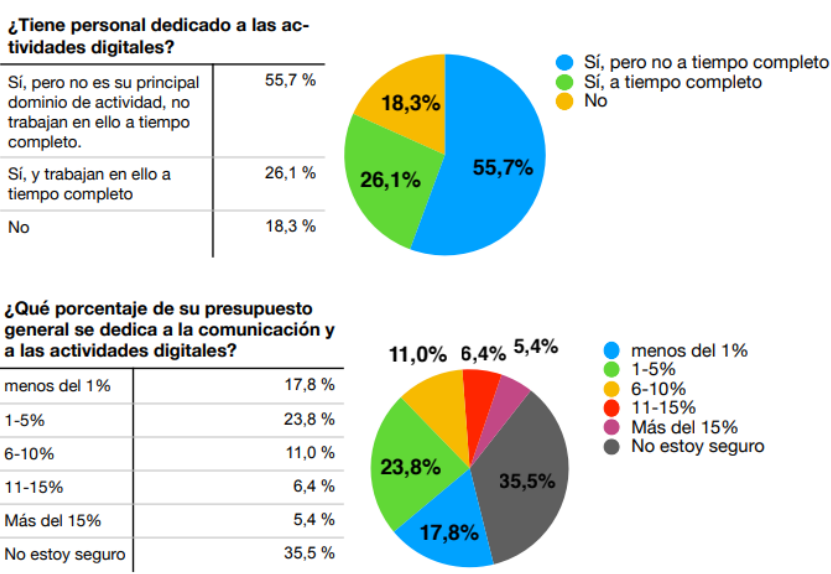

Gráfico realizado por la ICOM respecto a las actividades digitales y la comunicación. En este se puede observar que solo $26,1 \%$ del personal de las instituciones culturales dedican su jornada en exclusiva a la comunicación digital frente al 55,7 \% que la comparten con otras actividades. Respecto a la inversión solo un $11,8 \%$ de las instituciones invierten entre un $11 \%$ y más del $15 \%$ del presupuesto en actividades digitales, mientras que la tónica general es dedicar entre un $1 \%$ y $5 \%$.

Al igual que nadie estaba preparado para una pandemia global, muchas instituciones tampoco estaban preparadas para un gran volumen de visitantes en sus plataformas digitales. El \#PradoContigo consiguió un éxito tan apabullante en su primera entrega que tuvieron que adquirir un mayor número de servidores para poder llegar a todos los usuarios que se conectaban en directo para disfrutar de sus videos. Esta falta de inversión en tecnología y en recursos humanos que tienen los departamentos de comunicación online (si tienen suerte de tener uno) de muchas instituciones culturales es el mayor hándicap para la creación de iniciativas enfocadas a este campo. Como se puede observar en el informe del ICOM (2020a), a pesar de que las comunicaciones digitales se han visto incrementadas un $15 \%$ y hasta un $50 \%$ en RRSS, solo un 26,1\% de las instituciones tiene personal que se dedica exclusivamente a ellas y solo un $11,8 \%$ destina entre un $11 \%$ y más del $15 \%$ del presupuesto a ellas. Una tendencia que debe de cambiar si se pretende que las instituciones culturales tengan una repercusión, una buena presencia y una buena comunidad en la red. A pesar de que un nuevo estudio del ICOM (2020b), publicado recientemente, 
recalca el interés de las instituciones por aumentar su oferta digital y, lo que es más importante, en repensar su oferta digital, la mayoría de estas continúan estando mal equipadas y la actualización se verá parada debido a la crisis económica que ha traído la pandemia.

En conclusión, este último año ha sido complejo y las instituciones culturales españolas han hecho todo lo posible para distraer a millones de personas que se han visto encerradas en casa durante meses. Se ha evolucionado y cambiado muchas prácticas en pocos meses, pero esto no debe convertirse en un punto y aparte. Se debe seguir adelante y apostar por la tecnología y por un personal cualificado que se pueda dedicar en exclusiva a un plan de comunicación digital, el cual tendrá a los usuarios y a los contenidos como principales ejes. Se trata de un camino complicado, lleno de continuas actualizaciones y de muchos errores, pero sin unos puntos bien definidos y marcados las instituciones lo tendrán complicado para adaptarse a los continuos cambios que se producen en las comunicaciones digitales.

\section{NOTAS}

1. Proyecto El Prado contigo. Desde el 12 de marzo hasta el 5 de junio de 2020. Disponible en: https://www. museodelprado.es/recurso/el-prado-contigo/894ec21c8ba2-a39b-30a9-b4859670eeb1 [Consulta: 04/12/2020]

2. Resultados en Instagram de la iniciativa \#RepteArtACasa. Disponible en: https://www.instagram.com/explore/tags/repteartacasa/ [Consulta: 04/12/2020]. Me gustaría puntualizar que esta propuesta no es nueva; se trata de un mecanismo ya utilizado por otras instituciones como el Getty Museum con \#GettyMuseumChallenge o la cuenta de instagram @tussenkunstenquarantaine

\section{BIBLIOGRAFÍA}

- Chic Pujol, L. (2018) Principales retos de las instituciones culturales con la comunicación online en la revolución 2.0. Culturas. Revista de Gestión Cultural, vol. 5, n. 2, pp. 20-28. Disponible en: https://polipapers.upv.es/index.php/cs/article/ view/10793/10730 [Consulta: 04/12/2020]

- ICOM (2020a) Informe. Museos, profesionales de los museos y COVID-19: resultados de la encuesta. Disponible en: https://icom.museum/wp-content/uploads/2020/05/Informemuseos-y-COVID-19.pdf [Consulta: 19/11/2020]

- ICOM (2020b) Informe. Museos, profesionales de los museos y COVID-19: encuesta de seguimiento. Disponible en: https://icom. museum/wp-content/uploads/2020/11/FINALES_Follow-up-survey.pdf [Consulta: 23/11/2020]

- Kangin, L. (2019) The insider's Guide to How Museum Hack Does Growth Hacking with Michael Alexis. Growth Hackers, August 13. Disponible en: https://growthhackers.com/articles/ the-insider-s-guide-to-how-museum-hack-does-growthhacking-with-michael-alexis [Consulta: 04/12/2020]

- Simón Diez, A. (2020) As Personal as Viral: Reinventing Museums Communication. ICOM Voices, 21 de septiembre del 2020. Disponible en: https://icom.museum/en/news/ reinventing-museum-communication/ [Consulta: 18/11/2020]

- Tramullas, G. (2020) Los museos, hacia una mayor convivencia física y digital. El Periodico, 28 de marzo. Disponible en: https://www.elperiodico.com/es/cuaderno/20200328/futuromuseos-tras-crisis-coronavirus-7906604 [Consulta: 06/11/2020] 